\title{
An effective approach to enhance the balancing control in bycycorobot using the soft computing techniques
}

\author{
Aswant Kumar Sharma, Dhanesh Kumar Sambariya \\ Department of Electrical Engineering, Rajasthan Technical University, Rajasthan, India
}

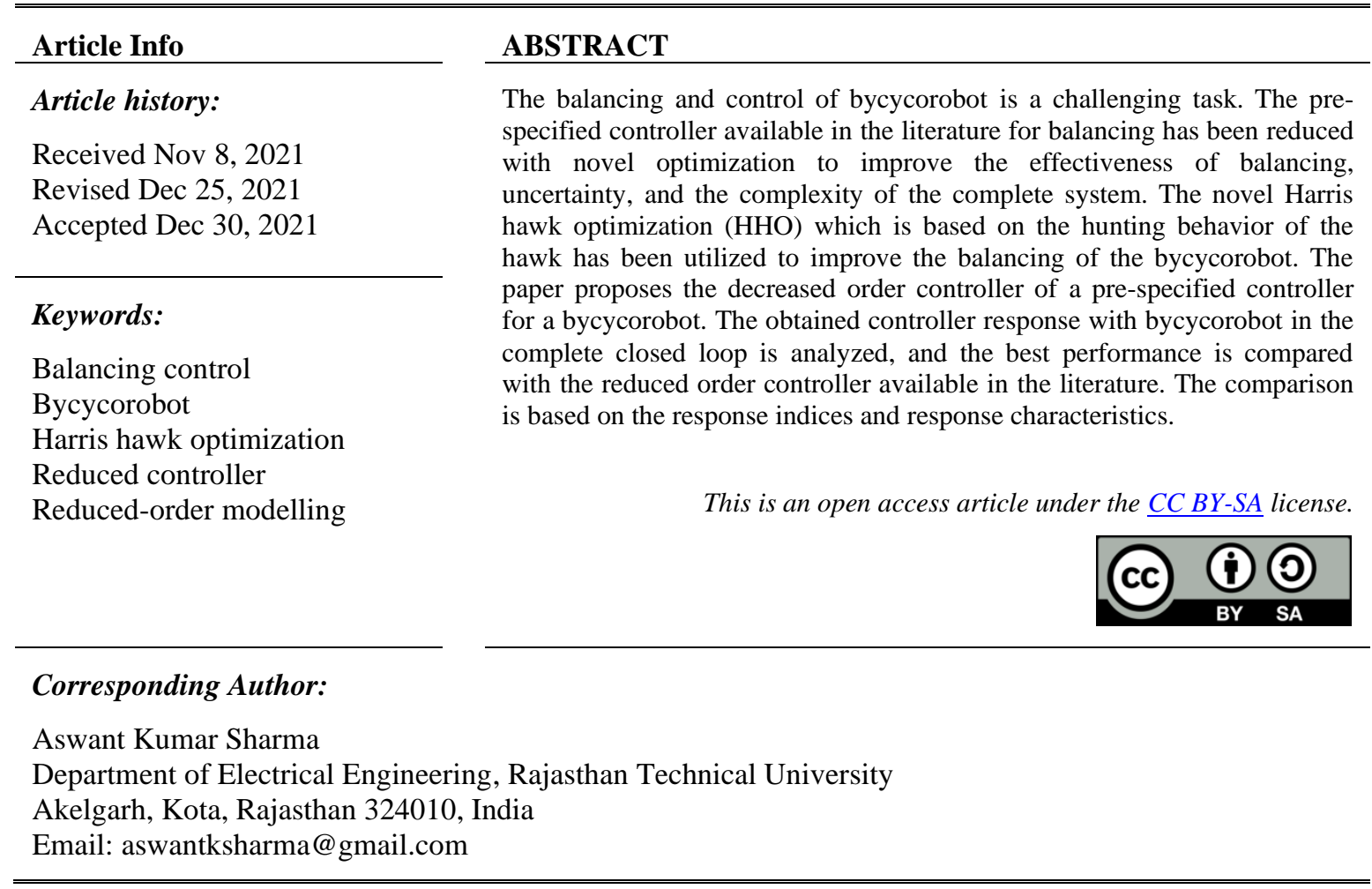

\section{INTRODUCTION}

As the first kind of personal mobility vehicle ever invented, bicycles play an important role in the history of transport. Bicycles are lightweight and are solely propelled by human power. They can contribute to the reduction of traffic congestion and air pollution in urban areas. Bicycles are classified as single-track vehicles and display interesting dynamic behavior. The intriguing behavior of bicycles poses challenging problems in modeling and control, which have attracted attention from the automatic control research community [1]. The balancing control problem of the bycycorobots is not new in the field of robotics. The bycycorobot is in great demand due to its basic construction, simpler dynamics, and applicability in wide sectors such as transportation, security, search and rescue, and labor reduction. These robots are inherently unstable and susceptible to external disturbances. Robust controls approached are required for appropriate and smooth balancing control and movement of such robots [2]. The stability of bicycles is an issue that has scarcely been understood in dynamics and is a commonly ignored problem. After two centuries of debate and unfinished modeling, new researches are paving the groundwork for increasing studies regarding this issue [3]. Thereby, some researchers have appeared thanks to new dynamics models and the computational power available nowadays. Their purpose is to propose and test different alternatives to stabilize a bicycle. Despite their common goal of making a bycycrobot stable, they propose a wide variety of applications for their stabilized bycycrobot [4].

The bicycle can be balanced using the rotation of the front wheel in the direction of lean, which changes the tire contact point with the ground in the same direction and is similar to balancing an inverted pendulum. In addition, the centrifugal force contributes to balance because of the circular motion. Moreover, uncontrolled bicycles can balance themselves within certain velocity ranges, which depend on different 
bicycle-design parameters [5]. For example, gyroscope, perturbation stationary bycycrobot system, inverted pendulum nonlinear controllers, robust two-stage active disturbance rejection control, fuzzy sliding-mode underactuated control, proportional derivative (PD) controllers, and proportional integral derivative (PID) controllers have been presented in distinctive researches [6]-[11]. The PID controller has three parameters to be tuned suitable for bycycrobot because of their degree of freedom-one for tilt, other for speed, and subject upon the applicability of the yaw. Numerous techniques are given in the literature for balancing control of bycycorobot like a flywheel, mass, and steering balancing [12]-[14]. Although much effort has been done to understand this fascinating phenomenon, the studies now have been restricted to a single situation in which the bicycle rides on a horizontal surface [15]. The adaptive integral terminal sliding mode was used to provide robust control of the reaction wheel of bycycorobot [16]. The proposed adaptive integral terminal sliding mode (AITSM) control scheme can not only stabilize the bicycle robot and reject external disturbances generated by uncertainties and un-modelled dynamics, but also eliminate the need of the required bound information in the control law via the designed adaptive laws. The experimental results verify the excellent performance of the proposed control scheme in terms of strong robustness, fast error convergence in comparison with other control schemes. The "scissor-pair control moment gyroscope technique" [17] for active balancing of the unmanned bicycle system. A miniature bicycle system was constructed, and its 3D solid model was used to acquire the dynamics model's parameter values. There are two types of disturbances that might cause a bicycle with an unstable equilibrium point to become unstable impulsive external disturbances and static continues disturbances. The experimental result depicts the performance of active balancing for a bicycle equipped with a scissor-pair control moment gyroscope (CMG) in the presence of such disturbances.

A bicycle robot balancing with steering and a non-inverted pendulum [18]. Euler-Lagrange equation of motion was used to create a nonlinear mechanical model of the bycycorobot moving at a constant forward speed, which was then linearized around the upright position. The pendulum and steering motor models were also included in the linearized mechanical model to obtain the complicated voltage-input system represented by the state-space model. The electro-mechanical parts of the robot were designed considering the controller for stabilizing the system. The simulation output revealed that the system with the pendulum-emphasized gain matrix outperformed the system with the steering-emphasized gain matrix in terms of learning and pathtracking ranges. The simulation results were, likewise, in line with the real outcome on the straight road and turning points.

One of the major problems in the development of bycycorobot is balancing at modest forward speeds. Therefore, Tofigh et al. [19] demonstrated a novel gyrostabilizer with a dual-flywheel configuration that can give any required gyroscopic roll moment. Extensive simulation comparison has been being carried out to assess the approach and demonstrate the impact of incorporating the new actuator. The result in [19] showed that the proposal provides higher performance while keeping the control effort within the capabilities of standard actuators. A structure-specified mixed " $\mathrm{H} 2 / \mathrm{H} \infty$ " controller was designed using particle swarm optimization (PSO) for control balancing of bycycorobot. The unstable system with many sources of uncertainty due to un-model dynamics, parameter variations, and external disturbances [20]. The design process, on the other hand, frequently generates a complicated and non-convex optimization issue that is difficult to address using traditional optimization approaches. PSO was a recently used meta-heuristic search approach for solving non-convex and multi-objective optimization problems. PSO was utilized in the approach to find parameters of a structure-specified controller that satisfy the combined $\mathrm{H} 2 / \mathrm{H} \infty$ performance index. The simulation and experimental findings demonstrate the proposed controller's resilience when compared to the traditional PD controller, as well as the suggested algorithms' efficiency when compared to the genetic algorithm (GA). Sikandar and Prasad [21] suggested combining reduced order modeling and a cuckoo search algorithm to develop a pre-specified structural controller for balancing control of two-wheeled mobile robot. A lower order pre-specified structural controller was created in this study, and it was found to be efficient enough to deal with unknown dynamics. The undetermined parameters of the proposed reduced order controllers are determined using the cuckoo search method. The suggested controllers' results $\mathrm{s}$ was compared to those of GA, PSO, Schur analysis, balance truncation, model truncation and traditional PD controller. The proposed controller was found to have superior performance when compared to other controllers. In terms of time response requirements and performance indices such as integral of square error (ISE), time-weighted integral of absolute error (ITAE), integral of absolute error (IAE), the performance of higher and lower controllers was also investigated using a perturbed two-wheeled mobile robot.

Controlling the equilibrium of a bycycorobot is a particularly tough task. Many balance control methods for two-wheeled bicycles have been suggested including non-linear control, compensator design utilizing the roots' locus techniques, PD control, PID control, and fuzzy control. However, these control algorithms are not robust; the two-wheeled bicycle model cannot bear varying weight loads and cannot bear varying weight loads and cannot operate in noisy situations. As a result, a robust control method is 
appropriate for the real-world applications of the two-wheeled bicycle model for this, composite method $\mathrm{H} 2 / \mathrm{H} \infty$ control is presented, which is a sophisticated approach for constructing durable and optimum controllers for systems with unknown sources. However, it is widely understood that the structure-specified mixed $\mathrm{H} 2 / \mathrm{H} \infty$ controller design typically creates a complicated and non-convex optimization issue that is difficult to address using traditional optimization methods. The optimization approaches using GA, PSO, and Cuckoo search have been suggested to tackle this problem. These techniques have offered to balance but the improvement of balancing also has the possibility in bycycorobot against uncertainty and external disruption. The reason of unmolded dynamics, parameter changes, and external disturbances complicates the system and necessitates a strong controller. As a result, a novel approach is required to enhance the balance control in bycycorobot.

The model order reduction methodology has been applied in order to obtain the reduced order controller. The MM techniques [22], continued fraction [23], mixed methods [24]-[28] are traditional methods tested and failed. The main objective of this manuscript is to obtain the effectively reduced order controller with bycycorobot response and enhance the balance control of it under uncertainty and external disturbances. For this, Harris hawk optimization (HHO) is having been selected due to aggressive and swarm behavior to design the controller efficiently. The approach represents the systems' model uncertainty as multiplicative uncertainty, and the system is considered to be influenced by external disturbances. HHO has been utilized for search parameters of and admissible structure-specified controller that minimizes the ISE while being subjected to robust stability constraints $(\mathrm{H} \infty$ norm) against model uncertainty and external disturbances. The suggested method is used to regulate the balance of a bicycle robot equipped with a gyroscopic stabilizer, known as bycycorobot. Using the Lagrange technique, a simplified dynamics model of a bycycorobot is constructed by disregarding forces caused by forwarding movement and steering. To evaluate the performance proposed system, it was compared with other techniques available in the literature. The proposed system is implemented using MATLAB software. The proposed algorithm-based controller will be effectively enhanced the performance of the balancing control in bycycorobot which is an unstable system with un-modeled dynamics, parameter changes, and external disturbances as sources of uncertainty.

\section{HARRIS HAWK OPTIMIZATION (HHO)}

HHO is based on the studies of hawk behavior usually in the period of hunting. The study has been carried out by Louis Lefebvre. The mathematical implementation in the engineering designing field using the HHO is carried out [29]. The behavior of hunting and chasing patterns for the capture of prey in nature is known as a surprise pounce. The searching of prey is a task done by the predator using the highest point of the area such as standing on top of trees or flying in the sky. The attack of the hawk on prey is called a pounce. As the prey is spotted another member is informed by visual displaying or vocalization. The HHO is divided into three-phase naming exploration, the transition from exploration to exploitation, and the exploitation phase. The exploitation stage is separated into four stages namely soft besiege, hard besiege, soft besiege with advanced quick dives, and hard besiege with progressive speedy dives. Figure 1 is showing the flow chart of HHO.

\subsection{The exploration phases}

To start this phase, the Hawk reaches the peak of tree/pole/top of the hill to trace the prey and also consider the other of Hawks positions. The situation is $q \geq 0.5$ of branch on random giant trees for the situation of $\mathrm{q} \leq 0.5$. The condition ids are modeled as (1).

$$
x(t+1)=\left\{\begin{array}{c}
x_{\text {rand }}(t)-r_{1}\left|X_{\text {rand }}(t)-2 r_{2} X(t)\right| q \geq 0.5 \\
\left(X_{\text {prey }}(t)-X_{m}(t)-r_{3}\left(L B+r_{4}\left(U B_{L B}\right)\right)\right) q \leq 0.5
\end{array}\right.
$$

Where $X(t+1)$ is the position vector of the hawk in the succeeding iteration $t . X_{\text {prey }}(t)$ is the present position vector of hawks $r_{1}, r_{2}, r_{3}, r_{4}$ and $q$ are the random number confidential $(0,1)$ upgraded with iteration. LB is the lower bounds, and UB is the upper bounds of numbers $X_{\text {rand }}(t)$ represents the arbitrarily hawk represents the arbitrary hawk from the present population $X_{m}$ is the average position of the current population is the average position of the current population of hawks. The primary rule creates solutions based on a random position. In the second rule of (1), the variance between the best positions and the average location of the group plus an arbitrary climbed factor depends on the number of variables. The scaling factor $r_{3}$ increases the random nature of regulation once $r_{4}$ adjacent value to 1 adjacent value to 1 and comparable distribution designs. Random factor scaling coefficients increase pattern diversification and explore various feature regions. The rules for buildings are capable of mimicking the actions of a hawk. The hawk's average location is obtained using (2).

An effective approach to enhance the balancing control in bycycorobot using ... (Aswant Kumar Sharma) 


$$
X_{m}(t)=\frac{1}{M} \sum_{i=1}^{M} X_{i}(t)
$$

Where $X_{m}(t)$ is obtaining by (2) $X_{i}(t)$ designates the position of an individual hawk in iteration $t$ and $N$ signifies the number of hawks.

\subsection{Conversion from exploration to exploitation}

The exploration to exploitation changes between exploitation performances founded on the absconding energy of the prey. The energy of a prey reduces throughout the escaping. The energy of the prey is modeled as (3).

$$
E=2 E_{0}\left(1-\frac{t}{T}\right)
$$

Where $E$ designates the absconding energy of prey, $T$ is the maximum number of iterations, and $E_{0}$ is the initial state of energy.

\subsection{Exploitation phase}

The process begins with the surprise, and the imagined prey of the previous stage is hostile. The preys try to escape. The probability of fleeing from the prey is $(r<0.5)$ or not to escape efficaciously $(r \geq 0.5)$. The hawk executes rough or soft besieges concerning prey activity to capture the prey. Based on the vitality of the prey, the hawk encircles around the beast in various ways. The hawk gets closer to the desired prey to maximize its odds of cooperating in killing the rabbit. The gentle assault begins, and the rough assault takes place.

\subsection{Besiege occurs}

Besiege is the process at the time of capturing prey. It is divided into soft besiege and hard besiege with progressive dives of each respectively.

\subsection{Soft besiege}

The prey has energy and tries to escape using random confusing jumps. The value for escaping energy must be $r \geq 0.5$ and $E \geq 0.5$. If the values are below as stated, the prey is unable to jump. Hawk encircles prey gently to make it more tired and achieve the surprise dive. This conduct is modeled by subsequent rules represented in (4) and (5).

$$
\begin{aligned}
& X(t+1)=\Delta X(t)-E\left|J * X_{\text {prey }}(t)-X(t)\right| \\
& \Delta X(t)=X_{\text {prey }}(t)-X(t)
\end{aligned}
$$

\subsection{Hard besiege}

The prey is exhausted and has less energy when values $r \geq 0.5$ and $E \geq 0.5$. The hawk barely encloses the intended prey and finally achieves the shock pounce. The present locations are updated as (6).

$$
X(t+1)=X_{\text {prey }}(t)-E|\Delta X(t)|
$$

Dive is founded on the LF-based designs using the law represented in (7).

$$
Z=Y+S \times L F(D)
$$

Where $D$ represents the dimension problem and $S$ represents a random vector by size $1 \times D$ and $L F$ is the levy fight function, and calculated as (8).

$$
L F(x)=0.01 \times \frac{u \times \sigma}{|v|^{\frac{1}{\beta}}}, \sigma=\left(\frac{\Gamma(1+\beta) \times \sin \left(\frac{\pi \beta}{2}\right)}{\Gamma\left(\frac{1+\beta}{2}\right) \times \beta \times 2}\right)^{\frac{1}{\beta}}
$$

Where, $u, v$ are random values inside $(0,1), \beta$ is a constant set to 1.5 . The last tactic for apprising the locations of hawks. The soft besiege stage can be achieved and given in (9). 


$$
X(t+1)=\left\{\begin{array}{l}
Y \text { if } F(Y)<F(X(t)) \\
Z \text { if } F(Z)<F(X(t))
\end{array}\right.
$$

The $Y$ and $Z$ are obtained using the (8) and (9).

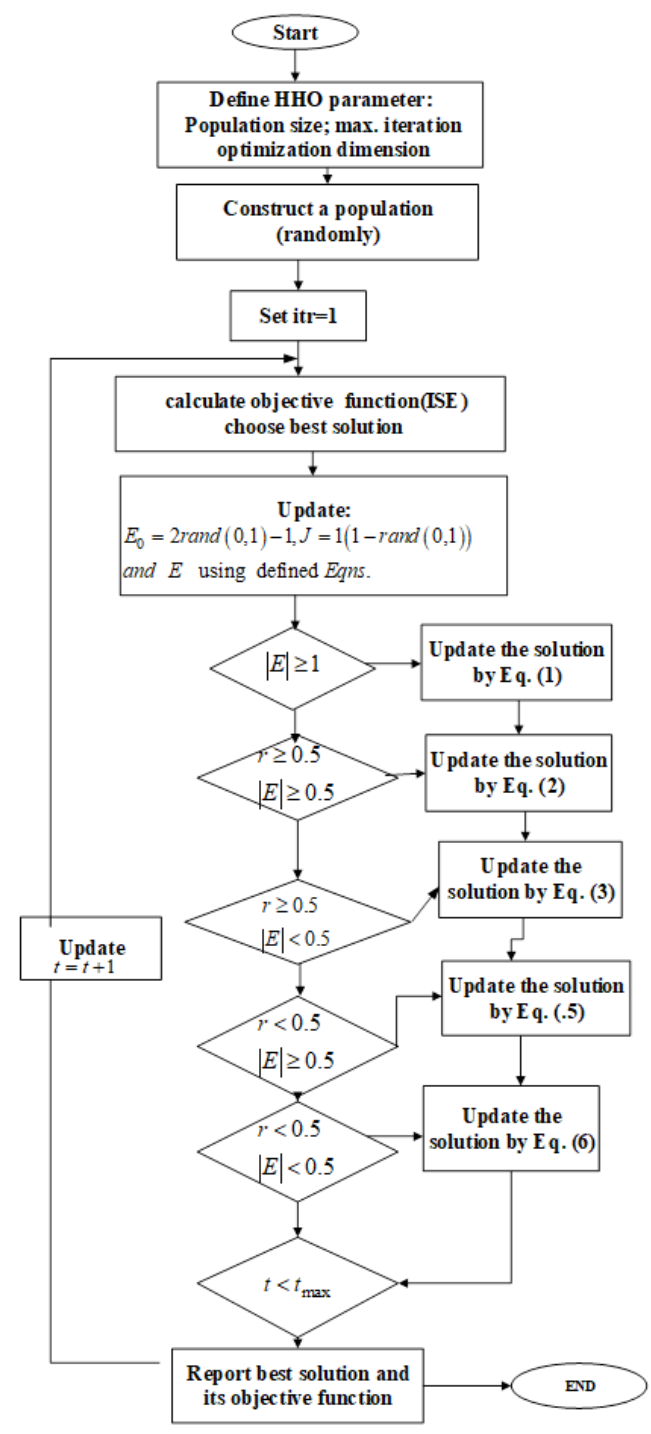

Figure 1. Flow chart of HHO

\subsection{Hard besiege with progressive dives}

The $|E|<0.5$ and $r<0.5$. To escape and hard besiege is built earlier the surprise pounce to catch and kill the prey. The condition on the prey side is comparable to that of soft besiege except this time. The hawk seeks to reduce the difference between their regular position and the fleeing target.

$$
X(t+1)=\left\{\begin{array}{l}
Y \text { if } F(Y)<F(X(t)) \\
Z \text { if } F(Z)<F(X(t))
\end{array}\right.
$$

The $Y$ and $Z$ are gained by (11) and (12).

$$
\begin{aligned}
& Y=X_{\text {prey }}(t)-E\left|J * X_{\text {prey }}(t)-X_{m}(t)\right| \\
& Z=Y+S \times L F(D)
\end{aligned}
$$




\section{MATHEMATICAL MODEL OF BYCYCOROBOT SYSTEM}

The bycycorobot is shown in Figure 2. Figure 2(a) is showing bicycle representation of bycycorobot for side view, Figure 2(b) is showing bicycle representation of bycycorobot for front view, Figure 2(c) is showing bicycle representation of bycycorobot for flywheel side view, Figure 2(d) is showing bicycle representation of bycycorobot for flywheel front view. Wheels are mounted on a different axis. The main task the goal of the robot is to move without falling in any direction, with or without limited load. The major issue of the taken task is of balancing because of its unstable nature and various uncertainties. Different controllers/ algorithms are available to resolve the problem. Bycycorobot dynamics is derived using the Langrage (13).

$$
\frac{d}{d t}\left\{\frac{\partial K E}{\partial \dot{f}_{i}}\right\}-\frac{\partial K E}{\partial f_{i}}+\frac{\partial P E}{\partial f_{i}}=E F_{i}
$$

Where $K E$ denotes the total kinetic energy, $P E$ represents the total potential energy of the system, $f_{i}$ is generalized coordinate, and $E F_{i}$ denotes the external forces. The $P E$ and $K E$ relation are (14)-(17) Bycycorobot dynamics are derived using the Langrage (14).

$$
\begin{aligned}
& P E=m_{r} g H_{r} \cos \alpha+m_{f} g h_{f} \cos \alpha \\
& K E=\frac{1}{2} M_{r}\left(\dot{\alpha}^{2} H_{r}^{2}\right)+\frac{1}{2} M_{f}\left(\dot{\alpha}^{2} h_{f}^{2}\right)+\frac{1}{2} I_{r} \dot{\alpha}^{2}+\frac{1}{2}\left[I_{m} \dot{\beta}^{2}+I_{f}(\dot{\alpha} \sin \beta)^{2}+I_{m}(\dot{\alpha} \sin \beta)^{2}\right] \\
& f_{i}=\alpha \\
& \ddot{\alpha}\left[\begin{array}{l}
m_{r} H_{r}^{2}+m_{f} h_{f}^{2}+I_{r}+ \\
I_{f} \sin ^{2} \beta+I_{m} \cos ^{2} \beta
\end{array}\right] \\
& +2 \sin \beta \cos \beta\left(I_{f}-I_{m}\right) \dot{\alpha} \dot{\beta}-=I_{f} \omega \dot{\beta} \cos \beta \\
& g\left(m_{r} H_{r}+m_{f} h_{f}\right) \sin \alpha
\end{aligned}
$$

Where, $M_{r}$ and $M_{f}$ represents the weight of bycycorobot and flywheel respectively. $\alpha$ represents the lean angle, $\dot{\alpha}$ denotes angular velocity in Z-axis, $\beta$ represents the angle of flywheel along Z1 axis, $\dot{\beta}$ is the angular velocity of the flywheel along $\mathrm{X}_{1}$ axis. $H_{r}$ is the height of center of gravity of bycycorobot, $h_{f}$ represents the height of flywheel center of gravity. $I_{m}, I_{f}$, and $I_{r}$ are flywheel radial movement of inertial, flywheel polar movement of inertial and robot movement of inertia respectively. The value of $f_{i}=\beta$ and the equation obtained in (18).

$$
\ddot{\beta} I_{m}-\alpha^{2}\left(I_{f}-I_{m}\right) \sin \beta \cos \beta=T_{m}-I_{f} \omega \dot{\alpha} \cos \beta-V_{m} \beta
$$

The chain transmission of bycycorobot and DC Motor dynamics is assumed to be 5:1 and the relation obtained is given in (19) and (20).

$$
\begin{aligned}
& T_{m}=5 K_{m} i \\
& U=L \frac{d i}{d t}+R i+K_{e} \dot{\beta}
\end{aligned}
$$

Where in (19), $K_{m}$ represents the torque constant of motor and in (20) $K_{e}$ is back $e, m$, $f$. constant, $R$ and $L$ are armature resistance and inductance of motor. The equation (19) is substituted in (18) and linearizing (17) and (18) around the equilibrium point, the relation achieved as (21) and (22).

$$
\begin{aligned}
& \ddot{\alpha}\left[M_{r} H_{r}^{2}+M_{f} h_{f}^{2}+I_{r}+I_{m}\right]-g\left(\begin{array}{l}
M_{r} h_{r} \\
+M_{f} h_{f}
\end{array}\right) \dot{\alpha}-I_{f} \omega \dot{\beta}=0 \\
& \ddot{\beta} I_{m}+I_{f} \omega \dot{\alpha}+V_{m} \dot{\beta}-5 K_{m} i=0
\end{aligned}
$$



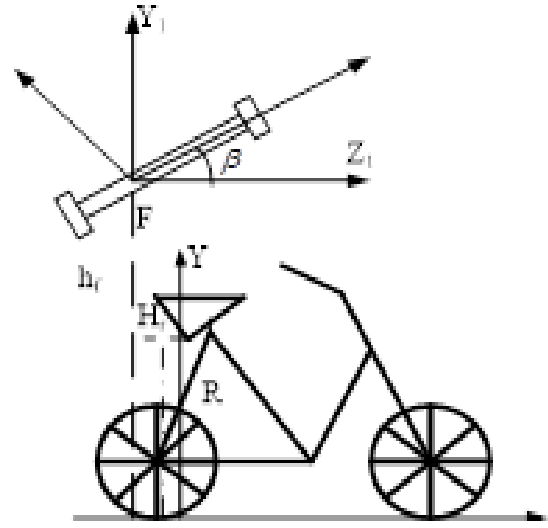

(a)

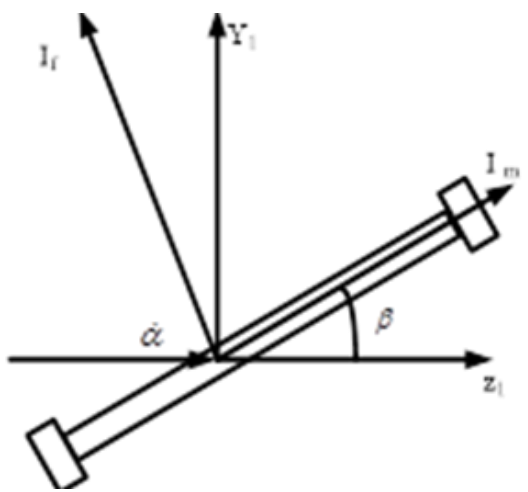

(c)

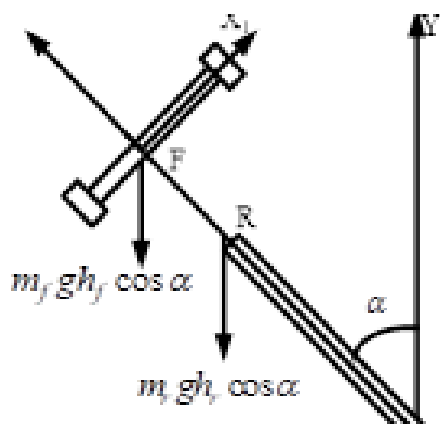

(b)

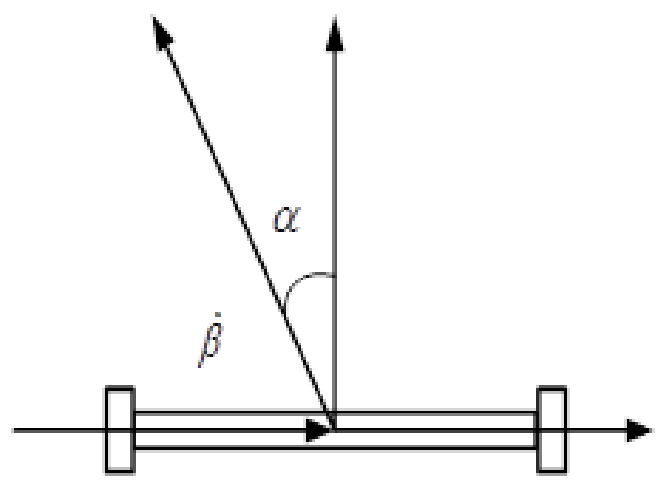

(d)

Figure 2. Bicycle representation of bycycorobot for (a) side view, (b) front view, (c) flywheel side view, and (d) flywheel front view

The consideration of the equation $x=\left[\begin{array}{cccc}\alpha & \dot{\alpha} & \dot{\beta} & i\end{array}\right]^{\prime}$ and $y=\alpha$ along with $u=U$. The state space equation of the system form is given in (23).

$$
\left\{\begin{array}{l}
\dot{x}=A x+B u \\
y=C x+D u
\end{array}\right.
$$

The values of the fourth order state space input part, output part is represented as (24)-(27).

$$
A=\left[\begin{array}{cccc}
0 & 1 & 0 & 0 \\
\frac{g\left(m_{r} h_{r}+m_{f} h_{f}\right)}{m_{r} h_{r}^{2}+m_{f} h_{f}^{2}+I_{r}+I_{m}} & 0 & \frac{I_{f} \omega}{m_{r} h_{r}^{2}+m_{f} h_{f}^{2}+I_{r}+I_{m}} & 0 \\
0 & -\frac{I_{f} \omega}{I_{m}} & -\frac{V_{m}}{I_{m}} & \frac{5 K_{m}}{I_{m}} \\
0 & 0 & -\frac{K_{e}}{L} & -\frac{R}{L}
\end{array}\right]
$$

$B=\left[\begin{array}{llll}0 & 0 & 0 & \frac{1}{L}\end{array}\right]$

$C=\left[\begin{array}{llll}1 & 0 & 0 & 0\end{array}\right]$

$D=[0]$

In most cases, a flywheel is used to balance the generated torque with respect to gravity. The parameter consideration of bycycorobot is listed in Table 1. 
Table 1. Parameter values

\begin{tabular}{lclc}
\hline \multicolumn{1}{c}{ Parameters } & Values & \multicolumn{1}{c}{ Parameters } & Values \\
\hline Mass of the robot $\left(m_{r}\right)$ & $8.1 \mathrm{~kg}$ & Height of robot centre of gravity $\left(H_{r}\right)$ & $0.86 \mathrm{~m}$ \\
Height of robot centre of gravity $\left(H_{r}\right)$ & $0.86 \mathrm{~m}$ & Robot moment of inertia & $27.548 \mathrm{kgm} \mathrm{m}^{2}$ \\
Robot moment of inertia & $27.548 \mathrm{kgm}^{2}$ & Mass of flywheel $\left(\mathrm{m}_{f}\right)$ & $43.1 \mathrm{~kg}$ \\
Flywheel polar moment of inertia & $0.215926 \mathrm{kgm}^{2}$ & Height of flywheel centre of gravity & $0.8 \mathrm{~m}^{2}$ \\
Torque constant of the motor $\left(K_{m}\right)$ & $0.119 \mathrm{Nm} / \mathrm{A}$ & Flywheel radial moment of inertia & $0.112304 \mathrm{kgm}^{2}$ \\
Flywheel speed $(\omega)$ & $157.08 \mathrm{rad} / \mathrm{s}$ & DC motor viscosity coefficient $\left(V_{m}\right)$ & $0.000253 \mathrm{kgm}^{2} / \mathrm{s}$ \\
Inductance of motor $(L)$ & $0.0006 \mathrm{H}$ & Back e.m.f constant of motor $\left(K_{e}\right)$ & $0.1184 \mathrm{Vs}$ \\
Mass of the robot $\left(m_{r}\right)$ & $8.1 \mathrm{~kg}$ & Armature resistance of motor $(R)$ & $0.41 \Omega$ \\
\hline
\end{tabular}

The state space into transfer function. The obtained transfer function of the two wheeled mobile robot is given as (28).

$$
G(s)=\frac{\alpha(s)}{U(s)}=\frac{4887}{s^{4}+683.3 s^{3}+1208 s^{2}+109700 s-6949}
$$

The output lean angle and the input voltage to the DC motor that controls the flywheel control axis. Assuming the following two cases: i) Case-1: the additional $10 \mathrm{Kg}$ load and decrease the speed of the flywheel up-to $147 \mathrm{rad} / \mathrm{sec}$. The transfer function from this condition is as (29); ii) Case-2: in this case, more $10 \mathrm{Kg}$ load is added speed of flywheel is increased to $167 \mathrm{rad} / \mathrm{sec}$. the transfer function is as (30).

$$
\begin{aligned}
& G_{1}(s)=\frac{3784}{s^{4}+683.3 s^{3}+1162 s^{2}+78290 s-6857} \\
& G_{2}(s)=\frac{4299}{s^{4}+683.3 s^{3}+1197 s^{2}+102300 s-6857}
\end{aligned}
$$

Bycycorobot including both the special case of the system represents instability in Figure 3 . The balancing control of the system is given by Thanh and Parnichkun in [20] with a controller based on particle swarm optimization using specifically mixed $\mathrm{H} 2 / \mathrm{H} \infty$ controller. The transfer function of the controller is as (31).

$$
\begin{aligned}
& 1275 s^{5}+8.695 \times 10^{5} s^{4}+5.151 \times 10^{5} s^{3} \\
& \begin{aligned}
G_{\left(H_{\infty}\right) c}(s)= & \frac{+1.359 \times 10^{8} s^{2}+2.435 \times 10^{7} s+1.091 \times 10^{6}}{s^{6}+715.7 s^{5}+2.355 \times 10^{4} s^{4}+2.789 \times 10^{5} s^{3}} \\
& +3.802 \times 10^{6} s^{2}+6.519 \times 10^{5} s+2.872 \times 10^{4}
\end{aligned}
\end{aligned}
$$

\section{DESIGN OF FIRST ORDER CONTROLLER USING HHO TECHNIQUE}

The structure of first order controller is obtained using the HHO by minimizing the ISE. The unknown reduced order model of first order is represented as (32).

$$
G_{C-\operatorname{Propsoed}}(s)=\frac{N_{1}}{1+D_{1}}
$$

The unknown value of the proposed first order controller is optimized using the Harris hawk algorithm. The important parameters lower bound (LB) is [150 1], upper bound (UB) is [200 160] number of iterations 100, search agents or hawks is 10. The obtained first order controller after 100 iterations in $353.148409 \mathrm{~s}$ is as (33).

$$
G_{C-\operatorname{Propsoed}}(s)=\frac{191.1806}{1+5.0382}
$$

The numerator, denominator parameter of first order controller optimized using the Harris hawk optimization and obtained result shown with iteration graph and response of proposed first order controller with sixth order and first order controller from literature given in Figure $4.1^{\text {st }}$ order controller with $6^{\text {th }}$ order $\mathrm{H}-\infty$ and $1^{\text {st }}$ order controller from literature for: i) Numerator as shown in Figure 4(a); ii) Denominator parameter as shown in Figure 4(b); iii) Fitness function as shown in Figure 4(c); and iv) Step response as shown in Figure 4(d). 


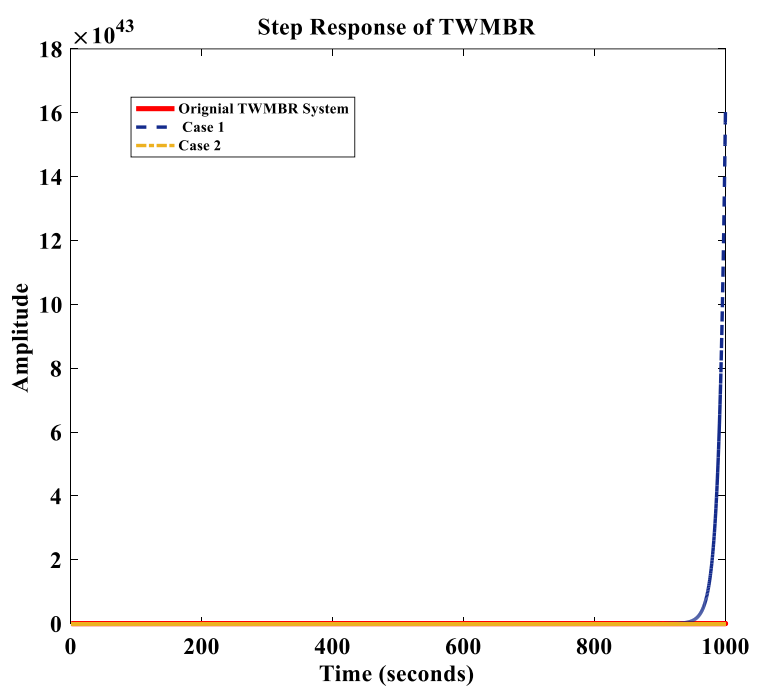

Figure 3. Step response of the bycycorobot (original, case-1 and case-2) without controller

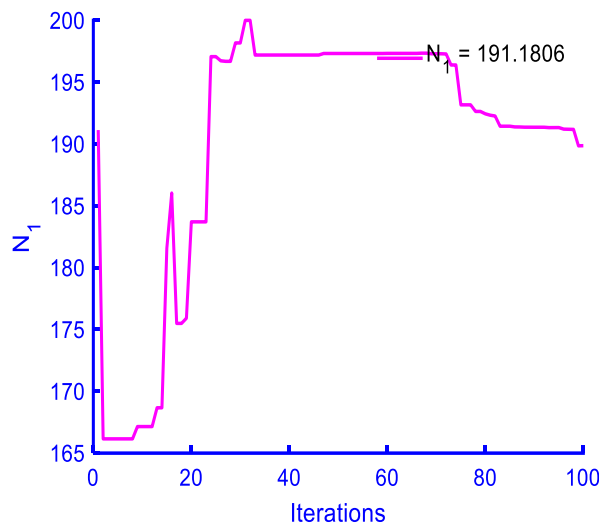

(a)

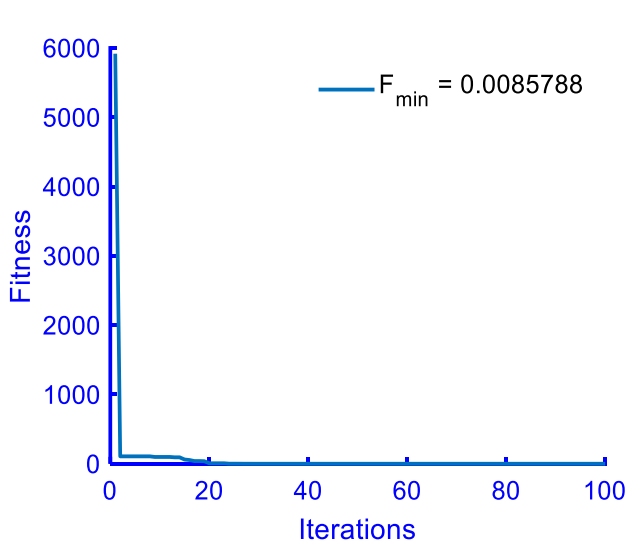

(c)

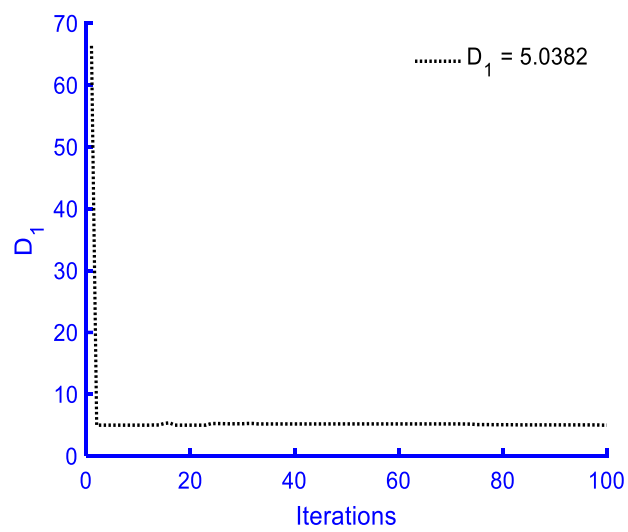

(b)

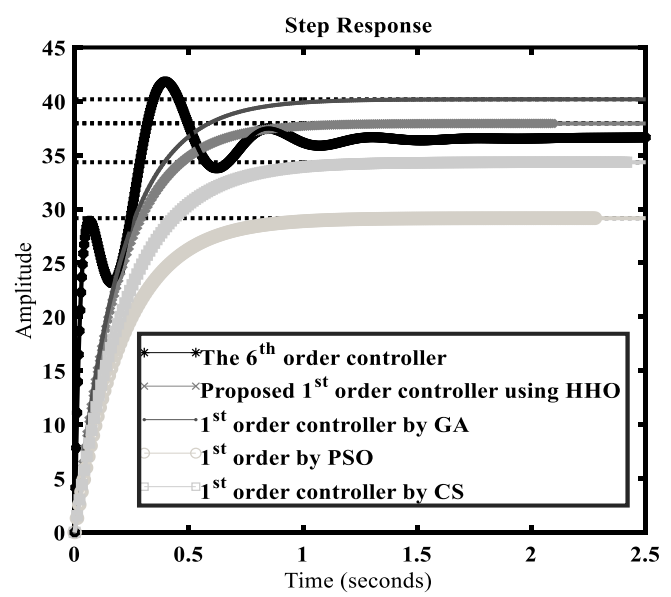

(d)

Figure 4. Proposed $1^{\text {st }}$ order controller with $6^{\text {th }}$ order $\mathrm{H}-\infty$ and $1^{\text {st }}$ order controller from literature for (a) numerator, (b) denominator parameter, (c) fitness function, and (d) step response

The $\mathrm{H}-\infty 6^{\text {th }}$ order controller response, shown in the blue step response and it contains some uncertainties and disturbance in the period of 0-1.5 s. The proposed first order controller using the HHO 
follows $\mathrm{H}-\infty$ controller closely and the uncertainties and disturbance are also removed. This indicates that in closed loop with bycycorobot in all three cases, it may perform with a better result. For Justification the response is also compared with the first order controller using GA and PSO [20] given as (34) and (35).

$$
\begin{aligned}
& G_{C-G A}=\frac{197.33}{s+4.91} \\
& G_{C-P S O}=\frac{196}{s+4.88}
\end{aligned}
$$
in $[21]$

Recently the first order controller with improved performance using the cuckoo search optimization

$$
G_{C-C S A}=\frac{150}{s+4.367}
$$

The first order controller with improved performance using PSO, the structure specified Hœ loop shaping controller in [30] and is given as (37).

$$
G_{C-P S O 1}=\frac{135}{s+4.63}
$$

The proposed controller needs to be tested and the response of it is compared with the controller available in the literature.

\subsection{First order controller closed loop analysis with bycycorobot}

The proposed first order controller in closed loop with the bycycorobot including the special case-1 and case- 2 has been analyzed in this part. The performance has been analyzed on the basis of step response characteristics and response indices error in Figure 4. The step response of the $1^{\text {st }}$ order controller using HHO with bycycorobot in a complete closed loop is represented in Figures 5-7 respectively.

The performance in terms of step response characteristics and response indices error of proposed first order controller with the system in closed loop with all cases available in Table 2. The proposed controller response is better than the first order controller using GA and PSO [20], Cuckoo search optimization in [21], the structure specified Ho loop shaping controller using PSO [30]. This can also be verified from the step response plot in Figure 5, Figure 6 for case-1, and Figure 7 for case- 2.

Table 2. Closed-loop performance of proposed $1^{\text {st }}$ order controllers with bycycorobot and its case- 1 , case- 2

\begin{tabular}{lcccc} 
System with controllers & \multicolumn{4}{c}{ Response indices error } \\
& ISE & IAE & ITAE & ITSE \\
\hline$G_{C-\text { Pr opsoed }}$ & 0.008372 & 0.1553 & 0.4408 & 0.007561 \\
Case 1 & 0.008372 & 0.1553 & 0.4408 & 0.007561 \\
Case 2 & 0.007634 & 0.1556 & 0.4703 & 0.007127 \\
$G_{C-G A}[20]$ & 0.01018 & 0.225 & 1.461 & 0.01385 \\
Case 1 & 0.0118 & 0.2547 & 1.766 & 0.01629 \\
Case 2 & 0.009557 & 0.2346 & 1.624 & 0.01453 \\
$G_{C-P S O}[20]$ & 0.02176 & 0.8046 & 31.27 & 0.2131 \\
Case 1 & 0.01196 & 0.255 & 1.753 & 0.01634 \\
Case 2 & 0.009659 & 0.2349 & 1.613 & 0.01455 \\
$G_{C-P S O 1}[30]$ & 0.03775 & 1.343 & 61.73 & 0.7739 \\
Case 1 & 0.03299 & 0.5856 & 7.03 & 0.1223 \\
Case 2 & 0.02768 & 0.5173 & 6.036 & 0.0926 \\
$G_{C-C S A}[21]$ & 0.0136 & 0.1547 & 0.2166 & 0.00881 \\
Case 1 & 0.01759 & 0.2749 & 2.342 & 0.02219 \\
Case 2 & 0.01312 & 0.2366 & 1.964 & 0.01599 \\
\hline
\end{tabular}

The data available in Table 2 concludes that the proposed controller is efficient and effective in all two cases and performs better. The controller analysis extended to the second order and its design using the HHO. 


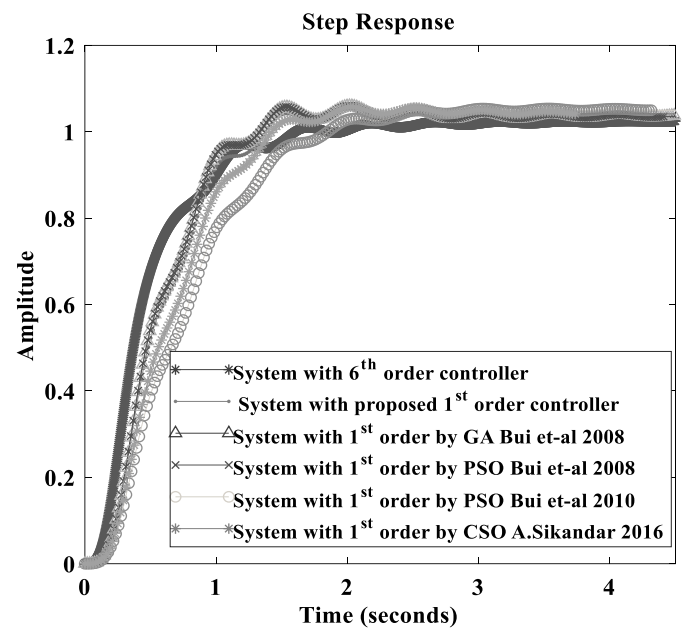

Figure 5. Step response characteristics of the proposed $1^{\text {st }}$ order controller in closed loop and first order controller from literature [20]-[22]

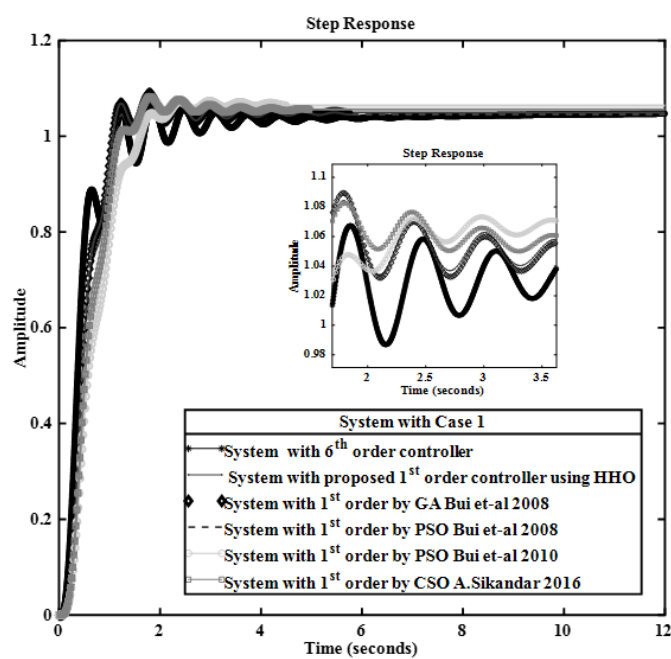

Figure 6. Step response characteristics of the proposed first order controller in closed loop case-1 and first order controller from literature [2]-[4]

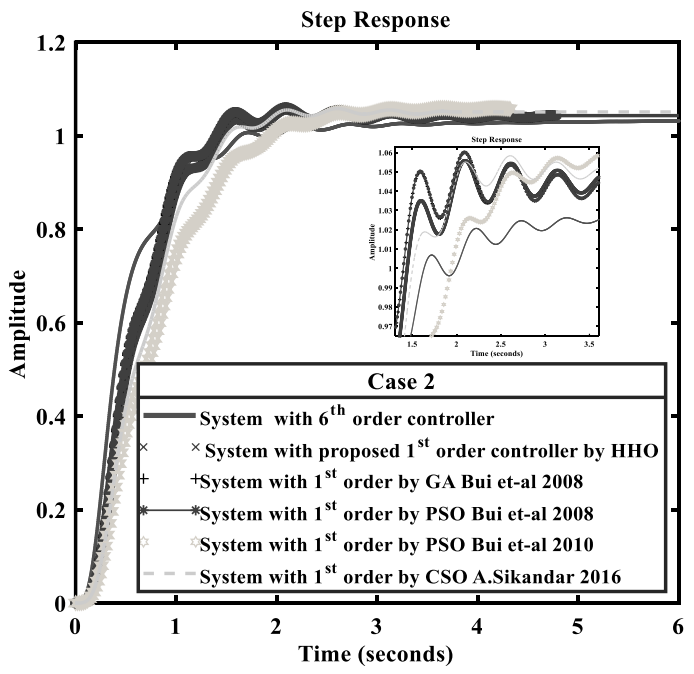

Figure 7. Step response characteristics of the proposed first order controller in closed loop case-2 and first order controller from the literature [2]-[4]

\section{DESIGN OF SECOND ORDER CONTROLLER USING THE HARRIS HAWK OPTIMIZATION}

The design of unknown second order reduced controller based on the structure of bycycorobot is represented as (38).

$$
G_{C-\operatorname{Proposed} 2}(s)=\frac{N_{1} s+N_{2}}{s^{2}+D_{1} s+D_{2}}
$$

The response analysis of the system with higher order controller and reduced controller from the literature the lower bound selected as $\mathrm{lb}=\left[\begin{array}{llll}230 & 950 & 8 & 20\end{array}\right]$; and upper bound selected as ub $=\left[\begin{array}{lllll}300 & 1000 & 10\end{array}\right.$ 30] with $N_{1}, N_{2}, D_{1}$ and $D_{2}$ are unknown four parameters dimensions which are to be optimized using an algorithm so dimension is 4 . The obtained parameter using the Harris hawk algorithm is represented in Figure 8, where Figure 8(a) is showing optimized numerator $\left(\mathrm{N}_{1}\right)$, Figure $8(\mathrm{~b})$ is showing optimized numerator $\left(\mathrm{N}_{2}\right)$, Figure $8(\mathrm{c})$ is showing denominator parameter values $\left(\mathrm{D}_{1}\right)$, and Figure $8(\mathrm{~d})$ is showing 
denominator parameter values $\left(\mathrm{D}_{2}\right)$. The obtained second order using the HHO algorithm is represented as (39).

$$
G_{C-\operatorname{Pr} \text { oposed } 2}(s)=\frac{292.2247 s+999.1637}{s^{2}+9.8363 s+26.3188}
$$

Figure 9 is showing the iteration graph of the controller with the fitness value and step response the higher order $\mathrm{H} \infty$ controller with the proposed reduced order, reduced order available in the literature is given in Figure 9(a). The step response in Error! Reference source not found.9(b), it is clear that the proposed $2^{\text {nd }}$ order reduced controller response approximately same as that of higher order controller and improved response from the controller from cuckoo search as (40) [21], and the second order controller using the PSO as (41) [30]. The effectiveness of the proposed order controller is also analyzed with the system in closed loop.

$$
\begin{aligned}
& G_{C-C S}(s)=\frac{266.5 s+891.6}{s^{2}+9.139 s+25.03} \\
& G_{C-P S O}(s)=\frac{129.7 s+499.6}{s^{2}+6.3835 s+16.18}
\end{aligned}
$$

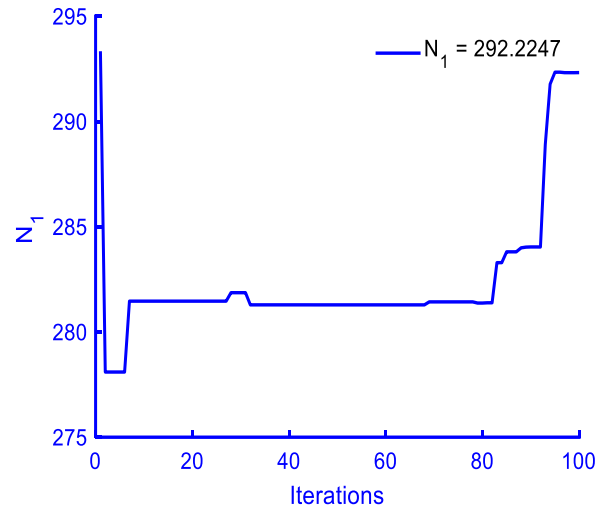

(a)

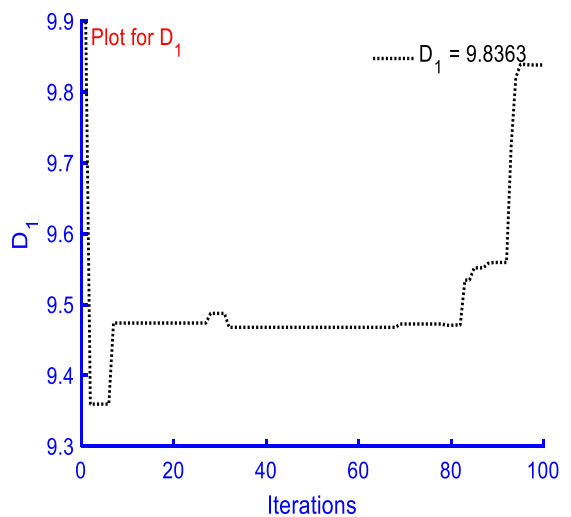

(c)

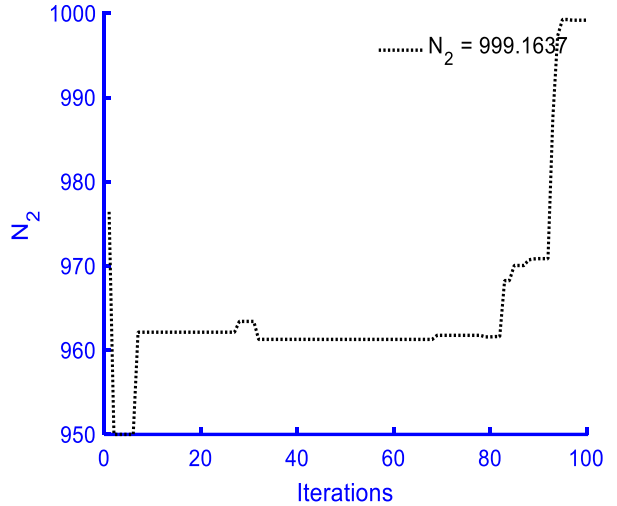

(b)

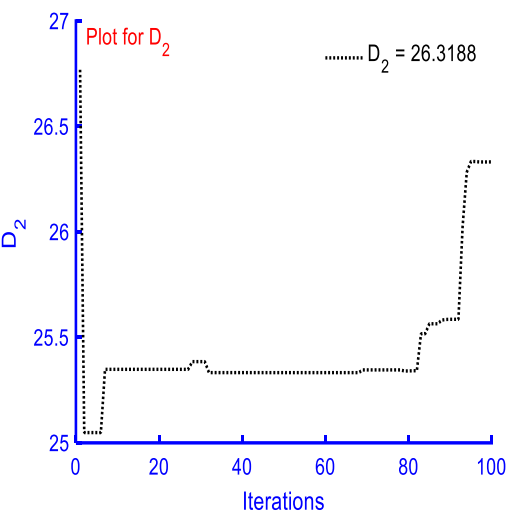

(d)

Figure 8. Harris hawk algorithm with a number of iterations for (a) optimized numerator $\left(\mathrm{N}_{1}\right)$, (b) optimized numerator $\left(\mathrm{N}_{2}\right)$, (c) denominator parameter values $\left(\mathrm{D}_{1}\right)$, and $(\mathrm{d})$ denominator parameter values $\left(\mathrm{D}_{2}\right)$ 


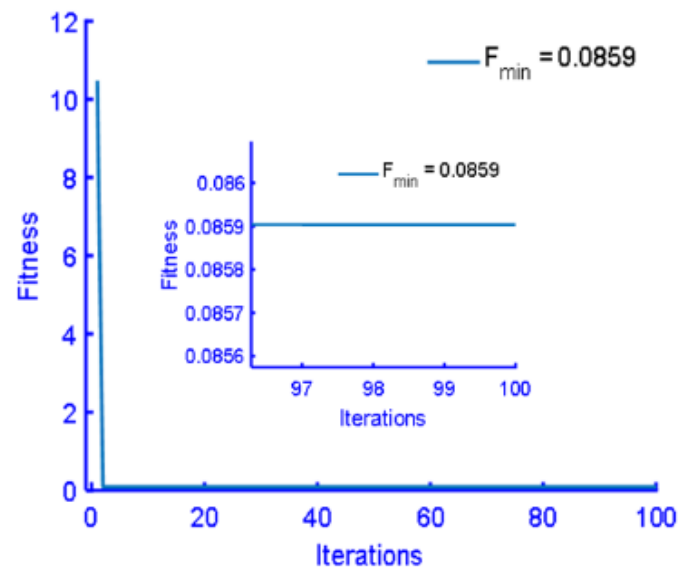

(a)

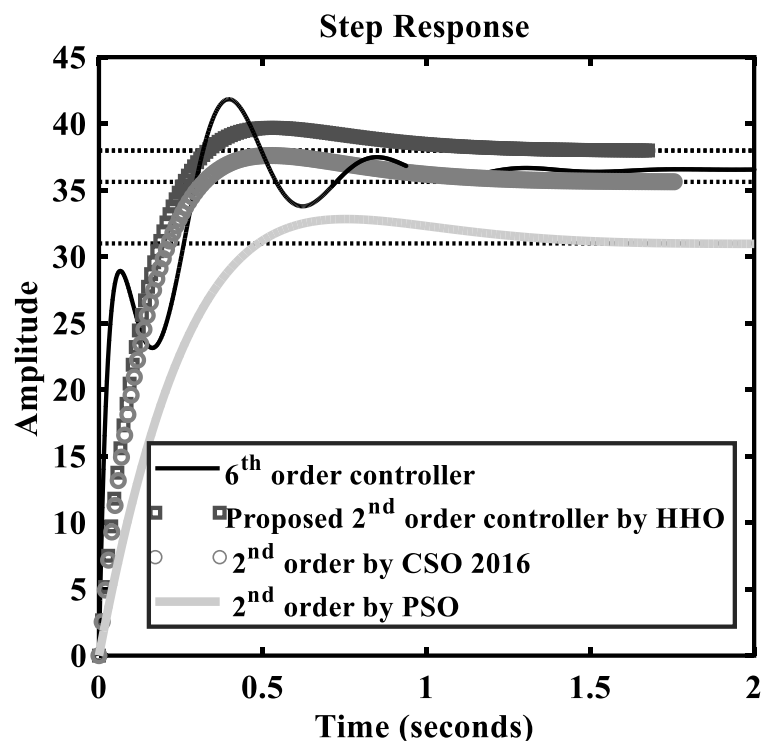

(b)

Figure 9. Iteration graph for (a) fitness value and (b) step response characteristics of higher order with proposed $2^{\text {nd }}$ order controller and $2^{\text {nd }}$ order controller from literature

\subsection{Second order controller closed loop analysis with bycycorobot}

The second order controller in closed loop with the bycycorobot stabilizes the system by removing uncertainties. The response of the controller with response characteristics and response indices error is given in Table 3.

The response of the proposed second order approximately gives the same response as that of the $6^{\text {th }}$ order controller with bycycorobot. Figure 10 is showing step response characteristics of the proposed second order controller in closed loop and second order controller from literature, Figure 11 is showing step response characteristics of the proposed second order controller in closed loop and second order controller from literature case-1, and Figure 12 is showing step response characteristics of the proposed second order controller in closed loop and second order controller from literature case-2.

The response is also justified with the result from the cuckoo search [21] and particle swarm optimization [30] It is clear from Table 3 that the proposed controller provides the comparable performance and the response indices IAE, ITAE and ITSE is better than the result from cuckoo search and particle swarm optimization. 
Table3. Closed-loop performance of proposed second order controllers with bycycrobot and its case-1 and case-2

\begin{tabular}{lcccc}
\hline System with controllers & \multicolumn{4}{c}{ Response indices error } \\
& ISE & IAE & ITAE & ITSE \\
\hline$G_{C-\text { Pr opsoed }}$ & 0.004346 & 0.1222 & 0.4305 & 0.004686 \\
Case 1 & 0.003511 & 0.1185 & 0.4399 & 0.003884 \\
Case 2 & 0.003414 & 0.1116 & 0.4181 & 0.003781 \\
$\left.G_{C-C S} 21\right]$ & 0.003304 & 0.1284 & 1.025 & 0.004934 \\
Case 1 & 0.00256 & 0.1303 & 1.349 & 0.005456 \\
Case 2 & 0.002491 & 0.123 & 1.162 & 0.00482 \\
$G_{C-P S O}$ 30] & 0.01567 & 0.3326 & 3.918 & 0.0401 \\
Case 1 & 0.02063 & 0.4242 & 5.222 & 0.06798 \\
Case 2 & 0.0157 & 0.3607 & 4.471 & 0.05039 \\
\hline
\end{tabular}

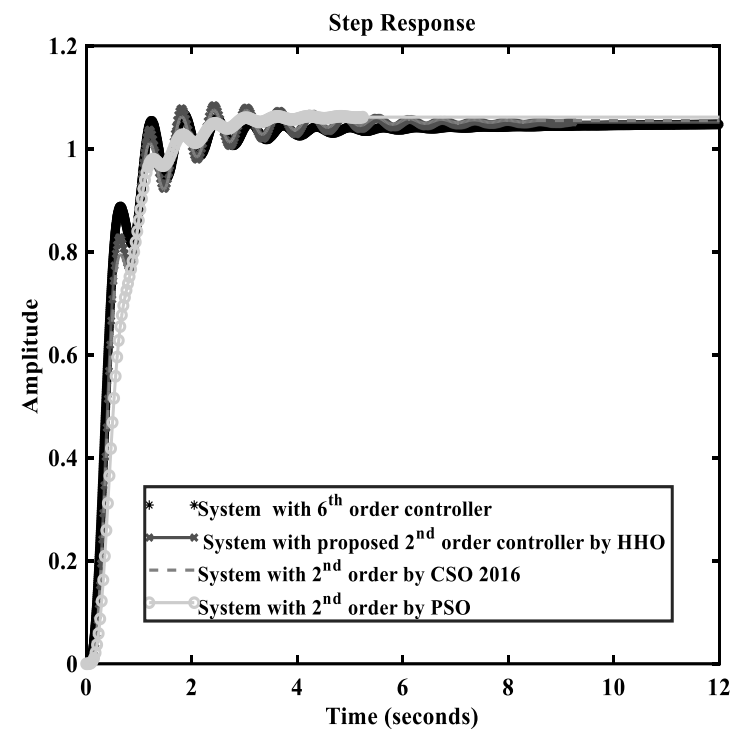

Figure 10. Step response characteristics of the proposed second order controller in closed loop and second order controller from literature

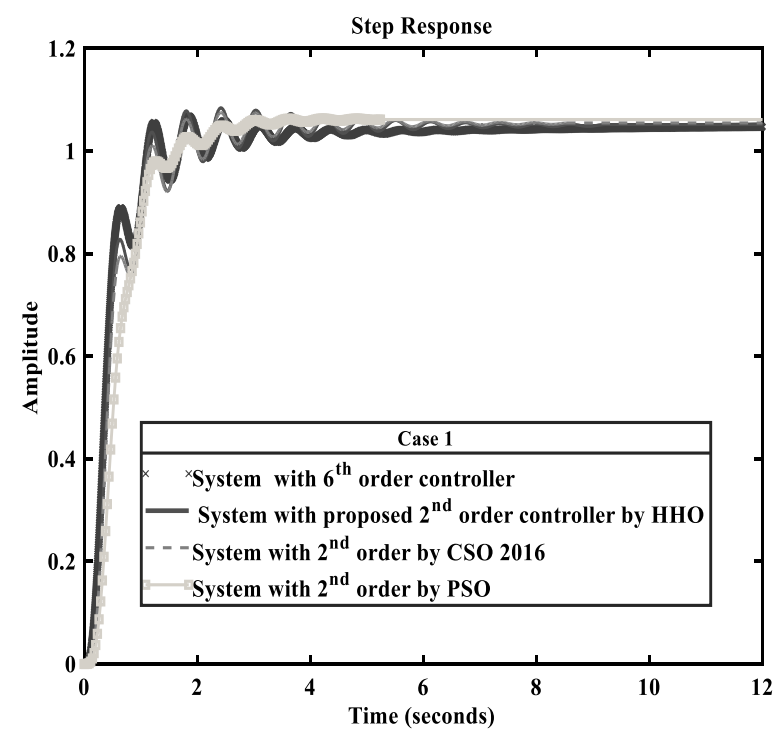

Figure 11. Step response characteristics of the proposed second order controller in closed loop and second order controller from literature case-1 


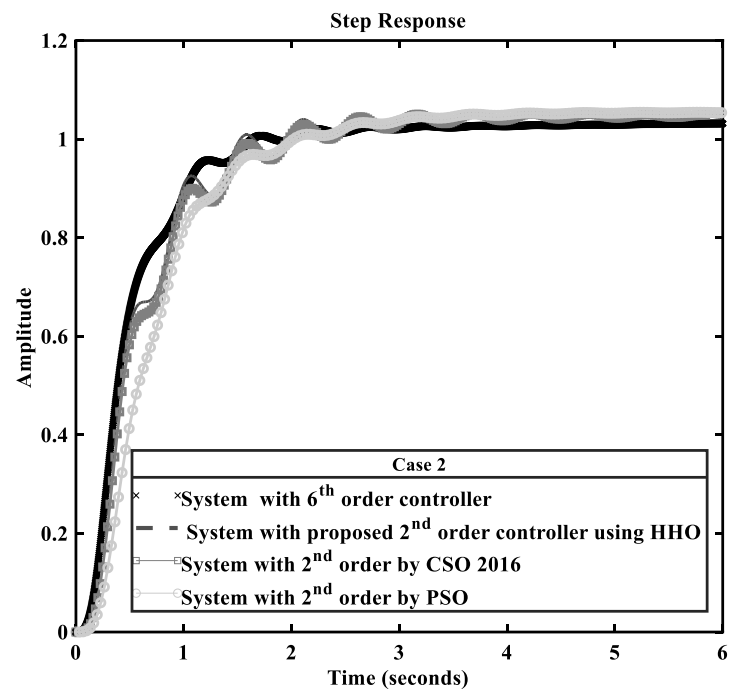

Figure 12. Step response characteristics of the proposed second order controller in closed loop and second order controller from literature case-2

\section{DESIGN OF THIRD ORDER CONTROLLER USING THE HARRIS HAWK OPTIMIZATION}

The third order controller with unknown is represented as (42).

$G_{C-\operatorname{Pr} \text { oposed } 2}(s)=\frac{N_{1} s^{2}+N_{2} s+N_{3}}{s^{3}+D_{1} s^{2}+D_{2} s+D_{3}}$

The value of unknown controller is optimized by HHO using lb = [1240 230193400303884470 ] and $\mathrm{ub}=\left[\begin{array}{ll}1270 & 240193900354007970\end{array}\right]$ with iteration of 100 and number of search agents are 10. The ISE is minimized in order to obtain the reduced order.

The unknown parameter of reduced order model is optimized and the obtained parameter is with respect to number of iterations is represented in Figure 13 and third order obtained as (43), Figure 13(a) is showing optimized numerator $\left(\mathrm{N}_{1}\right)$, Figure $13(\mathrm{~b})$ is showing denominator parameter $\left(\mathrm{D}_{1}\right)$, Figure 13(c) is showing optimized numerator $\left(N_{2}\right)$, Figure $13(d)$ is showing denominator parameter $\left(D_{2}\right)$, Figure $13(e)$ is showing optimized numerator $\left(\mathrm{N}_{3}\right)$, and Figure 13(f) is showing denominator parameter $\left(\mathrm{D}_{3}\right)$.

$$
G_{C-\operatorname{Pr} \text { oposed } 2}(s)=\frac{1259.294172 s^{2}+233.1976 s+193766.8479}{s^{3}+31.1049 s^{2}+394.9840 s+5276.281587}
$$

The third order reduced system using the Schur analysis, balanced truncation and model truncation given in [31], is represented as (44), (45), and (46).

$$
\begin{aligned}
& G_{C-S A}(s)=\frac{1275 s^{2}+234.8 s+1.993 e 5}{s^{3}+33.78 s^{2}+395 s+5506} \\
& G_{C-B T}(s)=\frac{1275 s^{2}+233.8 s+1.992 e 5}{s^{3}+33.78 s^{2}+395 s+5499} \\
& G_{C-M T}(s)=\frac{1057 s^{2}+226.5 s+1.6358 e 5}{s^{3}+27.99 s^{2}+395.9 s+4521}
\end{aligned}
$$

The proposed reduced order is analyzed with closed loop with the bycycorobot and equivalent reduced order from the literature [31]. The third order controller by cuckoo search algorithm [21], is represented as (47).

$$
G_{C-C S}(s)=\frac{1241 s^{2}+234.7 s+1.993 e 5}{s^{3}+32.47 s^{2}+395 s+5274}
$$




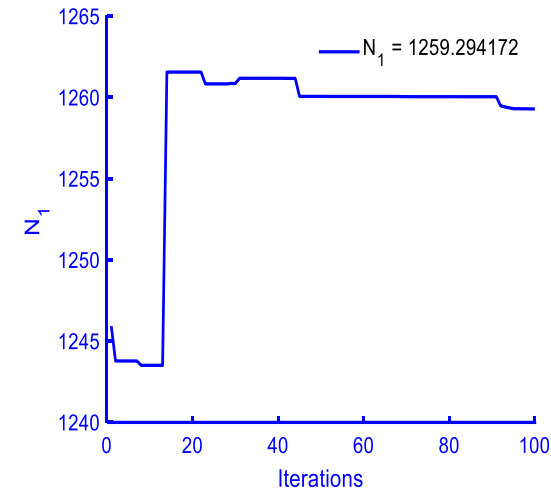

(a)

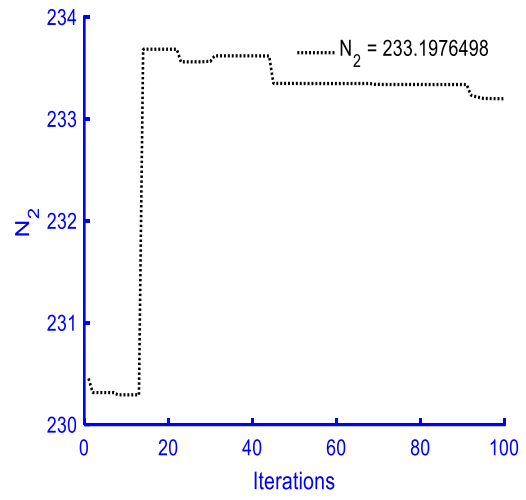

(c)

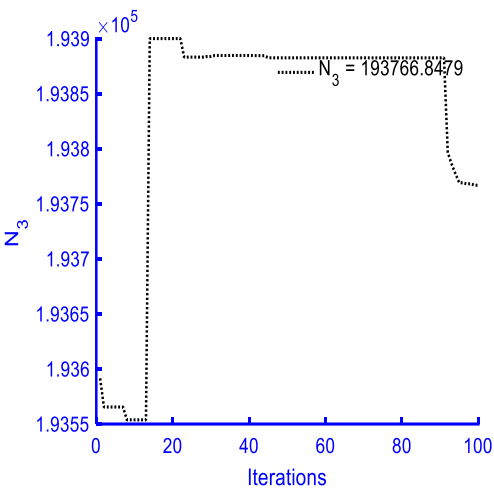

(e)

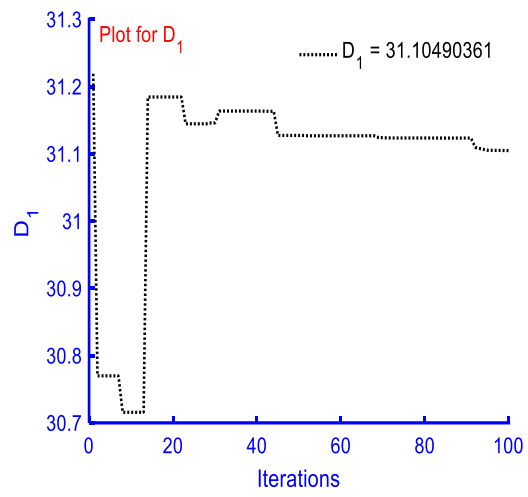

(b)

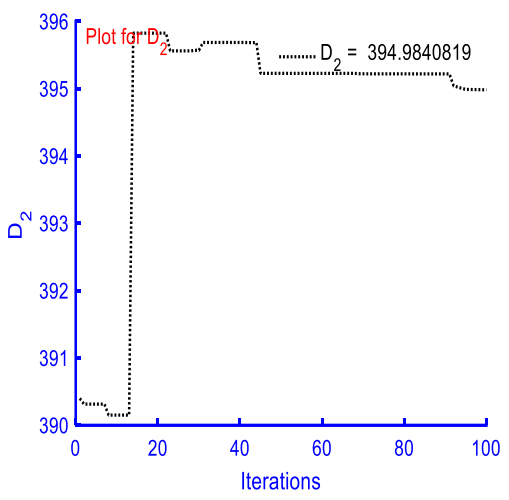

(d)

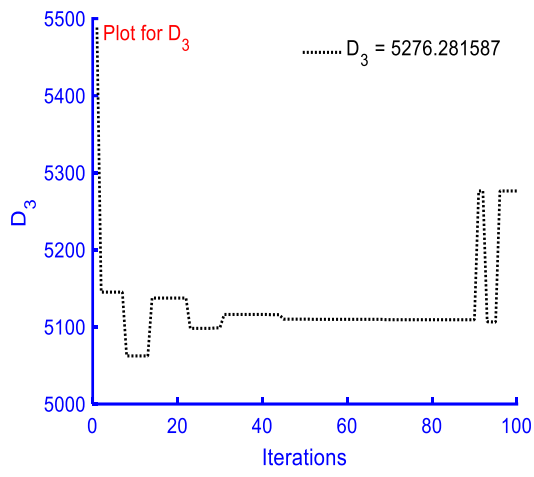

(f)

Figure 13. The Harris hawk algorithm with number of iterations for (a) Optimized numerator $\left(\mathrm{N}_{1}\right)$, (b) Denominator parameter $\left(\mathrm{D}_{1}\right)$, (c) Optimized numerator $\left(\mathrm{N}_{2}\right)$, (d) Denominator parameter $\left(\mathrm{D}_{2}\right)$,

(e) Optimized numerator $\left(\mathrm{N}_{3}\right)$, and (f) Denominator parameter $\left(\mathrm{D}_{3}\right)$

\subsection{Third order controller closed loop analysis with bycycorobot}

The proposed third order response has been analyzed with the system in closed-loop. The response of the system with the proposed controller in special cases is mentioned in Table 4 and compares with the response with the controller available in the literature [21], [31]. The third order proposed controller gives the approximate same response as compared to the controller present in literature [21], [31] and represents with step response characteristics in Figure 14, Figure 15 for case-1, and Figure 16 for case-2. The response indices IAE, ITAE and ITSE are minimum indicating the good approximation and superiority of the proposed reduced order justified. The approach has been verified with the pole location of the proposed first order, second order and third order controller with the result from the literature [20], [21], [30], [31]. Table 5 is showing poles of higher order and reduced order controller. 
Table 4. Step response characteristics and response indices error of proposed reduced controller in closed loop with system

\begin{tabular}{lcccc}
\hline \multirow{2}{*}{ System with controllers } & \multicolumn{4}{c}{ Response indices error } \\
& ISE & IAE & ITAE & ITSE \\
\hline$G_{C-3}$ rd Pr opsoed & $8.121 \mathrm{e}-5$ & 0.03723 & 0.4609 & 0.00005925 \\
Case 1 & 0.0001205 & 0.04514 & 0.6064 & 0.001008 \\
Case 2 & $8.782 \mathrm{e}-5$ & 0.04059 & 0.5273 & 0.0007553 \\
$G_{C-S A}[21],[31]$ & $7.472 \mathrm{e}-5$ & 0.04219 & 0.6628 & 0.001112 \\
Case 1 & 0.0001703 & 0.05152 & 0.8902 & 0.001961 \\
Case 2 & $9.283 \mathrm{e} 5$ & 0.04738 & 0.7647 & 0.001472 \\
$G_{C-B T}[21],[31]$ & $7.205 \mathrm{e}-5$ & 0.04131 & 0.6507 & 0.001073 \\
Case 1 & 0.0001032 & 0.05042 & 0.8733 & 0.00189 \\
Case 2 & $8.945 \mathrm{e}-5$ & 0.04639 & 0.7505 & 0.00142 \\
$G_{C-M T}[21],[31]$ & 0.0002247 & 0.04865 & 0.6664 & 0.00117 \\
Case 1 & 0.0005654 & 0.07986 & 0.9448 & 0.002514 \\
Case 2 & 0.0002393 & 0.05389 & 0.7687 & 0.001534 \\
$G_{C-C S}[21],[31]$ & 0.0003682 & 0.05164 & 0.2913 & 0.0007287 \\
Case 1 & 0.0004263 & 0.05369 & 0.3004 & 0.000834 \\
Case 2 & 0.0003882 & 0.055 & 0.3187 & 0.0008373 \\
\hline
\end{tabular}

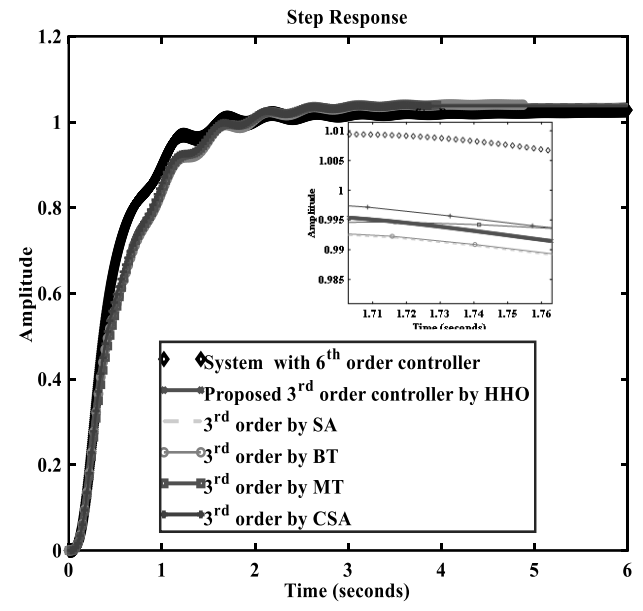

Figure 14. Step response characteristics of the proposed third order controller in closed loop and third order controller from literature

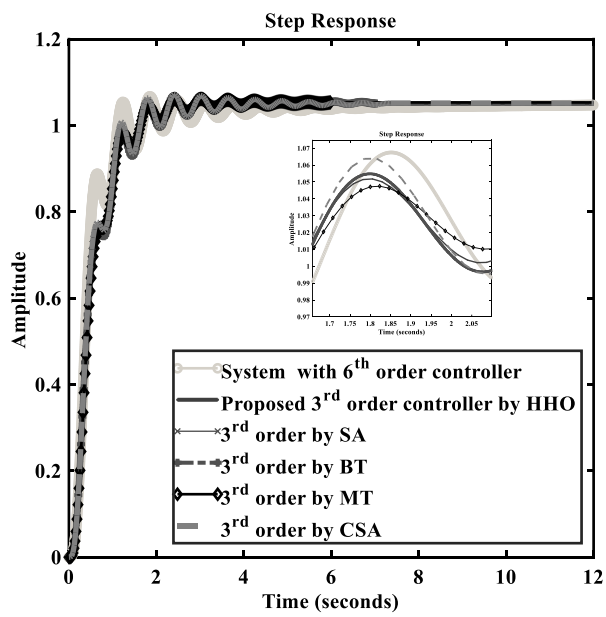

Figure 15. Step response characteristics of the proposed third order controller in closed loop and third order controller from literature case-1

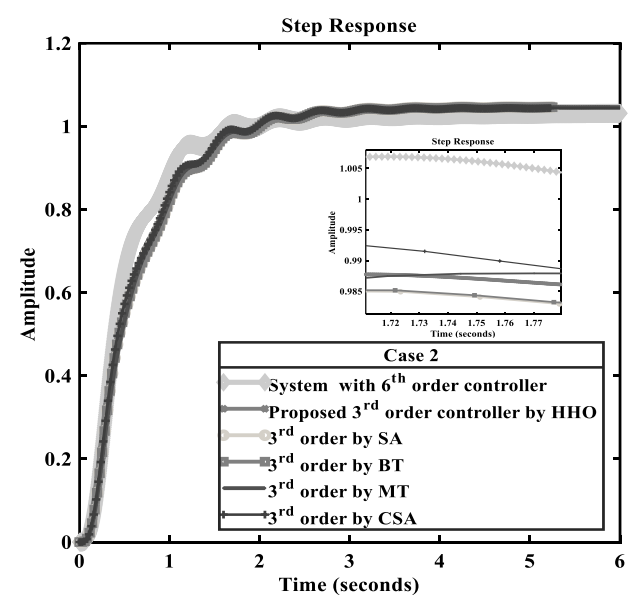

Figure 16. Step response characteristics of the proposed third order controller in closed loop and third order controller from literature, case-2 
Table 5. Poles of higher order and reduced order controller

\begin{tabular}{cccc}
\hline Controller & Poles & Controller & Poles \\
\hline $6^{\text {th }}$ Order & $-681.74+0.0000 \mathrm{i} ;-26.71+0.0000 \mathrm{i} ;-3.54 \pm 13.92 \mathrm{i} ;$ & $G_{C-C S}[21]$ & $-4.5695 \pm 2.0371 \mathrm{i}$ \\
$G_{C-\text { Propsoed }}$ & $-0.09 \pm 0.0001 \mathrm{i}$ & $G_{C-P S O}[31]$ & $-3.4175 \pm 2.1215 \mathrm{i}$ \\
$G_{C-G A}[20]$ & -5.0382 & $G_{C-3^{r d} \text { Propsoed }}$ & $-23.8219+0.0000 \mathrm{i} ;-3.6415 \pm 14.4301 \mathrm{i}$ \\
$G_{C-P S O}[20]$ & -4.9100 & $G_{C-S A}[21],[31]$ & $-26.7093+0.0000 \mathrm{i} ;-3.5354 \pm 13.9157 \mathrm{i}$ \\
$G_{C-C S A}[21]$ & -4.8800 & $G_{C-B T}[21],[31]$ & $-26.6997+0.0000 \mathrm{i} ;-3.5402 \pm 13.9077 \mathrm{i}$ \\
$G_{C-P S O 1}[30]$ & -4.3670 & $G_{C-M T}[21],[31]$ & $-19.5655+0.0000 \mathrm{i} ;-4.2123 \pm 14.6057 \mathrm{i}$ \\
$G_{C-P \text { opsoed } 1}$ & -4.6300 & $G_{C-C S}[21],[31]$ & $-25.1041+0.0000 \mathrm{i} ;-3.6830 \pm 14.0186 \mathrm{i}$ \\
\hline
\end{tabular}

\section{CONCLUSION}

The bycycorobot model balancing is achieved using the reduced order controller methodology. The sixth order controller is pre-specified in the literature. The controller when comes closed-loop with the system did not perform well, while in the complete closed-loop system, performance gets improved, while the order of the system in complete closed-loop increases to sixteen orders. Therefore, a reduced order controller is projected and successfully obtained using the HHO in the first, second, and third order. The result in a complete closed-loop is compared with the result of the higher-order controller, reduced order controller. The proposed controller not only balances the bycycorobot but also gives better performance in the first order, second order, and equivalent performance in third order as its performance is compared with the reduced order available in the literature.

\section{REFERENCES}

[1] C. F. Huang, Y. C. Tung, H. T. Lu, and T. J. Yeh, "Balancing control of a bicycle-riding humanoid robot with center of gravity estimation," Adv. Robot., vol. 32, no. 17, pp. 918-929, Sep. 2018, doi: 10.1080/01691864.2018.1509017.

[2] C. Xiong et al., "Static balancing of robotic bicycle through nonlinear modeling and control," in 2018 3rd International Conference on Robotics and Automation Engineering, ICRAE 2018, 2018, pp. 24-28, doi: 10.1109/ICRAE.2018.8586765.

[3] M. R. Garcia, D. A. Mantaras, J. C. Alvarez, and D. F. Blanco, "Stabilizing an urban semi-autonomous bicycle," IEEE Access, vol. 6, pp. 5236-5246, 2018, doi: 10.1109/ACCESS.2018.2795247.

[4] C. K. Chen, T. D. Chu, and X. D. Zhang, "Modeling and control of an active stabilizing assistant system for a bicycle," Sensors (Switzerland), vol. 19, no. 2, p. 248, Jan. 2019, doi: 10.3390/s19020248.

[5] S. peng Zhang and T. oh Tak, "A design sensitivity analysis of bicycle stability and experimental validation," J. Mech. Sci. Technol., vol. 34, no. 9, pp. 3517-3524, Sep. 2020, doi: 10.1007/s12206-020-0803-2.

[6] S. Batcir et al., "Development and piloting of a perturbation stationary bicycle robotic system that provides unexpected lateral perturbations during bicycling (the PerStBiRo system)," BMC Geriatr., vol. 21, no. 1, p. 71, Dec. 2021, doi: 10.1186/s12877-02102015-1.

[7] C. H. Chiu and C. Y. Wu, "Bicycle robot balance control based on a robust intelligent controller," IEEE Access, vol. 8, pp. 84837-84849, 2020, doi: 10.1109/ACCESS.2020.2992792.

[8] H. Gattringer, A. Reiter, A. Müller, D. Wagner, and T. Mauernböck, "Dynamical modeling and LQR control of a gyroscopically stabilized bicycle," PAMM, vol. 18, no. 1, Dec. 2018, doi: 10.1002/pamm.201800406.

[9] J. F. S. Trentin, S. Da Silva, J. M. De Souza Ribeiro, and H. Schaub, "Inverted pendulum nonlinear controllers using two reaction wheels: design and implementation," IEEE Access, vol. 8, pp. 74922-74932, 2020, doi: 10.1109/ACCESS.2020.2988800.

[10] M. Baquero-Suárez, J. Cortés-Romero, J. Arcos-Legarda, and H. Coral-Enriquez, "A robust two-stage active disturbance rejection control for the stabilization of a riderless bicycle," Multibody Syst. Dyn., vol. 45, no. 1, pp. 7-35, Jan. 2019, doi: 10.1007/s11044018-9614-y.

[11] C. L. Hwang, H. M. Wu, and C. L. Shih, "Fuzzy sliding-mode underactuated control for autonomous dynamic balance of an electrical bicycle," IEEE Trans. Control Syst. Technol., vol. 17, no. 3, pp. 658-670, May 2009, doi: 10.1109/TCST.2008.2004349.

[12] A. Jain, S. Bhaskar, K. Nandanwar, and H. O. Bansal, "Self-balancing of a bike using gyroscopic force and PID controller," in Intelligent Communication, Control and Devices. Advances in Intelligent Systems and Computing, vol. 989, S. Choudhury, R. Mishra, R. G. Mishra, and A. Kumar, Eds. Singapore: Springer, 2020, pp. 807-817.

[13] H. W. Kim, J. W. An, H. D. Yoo, and J. M. Lee, "Balancing control of bicycle robot using PID control," in International Conference on Control, Automation and Systems, 2013, pp. 145-147, doi: 10.1109/ICCAS.2013.6703879.

[14] Y. Kim, H. Kim, and J. Lee, "Stable control of the bicycle robot on a curved path by using a reaction wheel," J. Mech. Sci. Technol., vol. 29, no. 5, pp. 2219-2226, May 2015, doi: 10.1007/s12206-015-0442-1.

[15] J. Xiong, N. Wang, and C. Liu, "Bicycle dynamics and its circular solution on a revolution surface," Acta Mech. Sin. Xuebao, vol. 36, no. 1, pp. 220-233, Feb. 2020, doi: 10.1007/s10409-019-00914-6.

[16] L. Chen et al., "Robust control of reaction wheel bicycle robot via adaptive integral terminal sliding mode," Nonlinear Dyn., vol. 104, no. 3, pp. 2291-2302, May 2021, doi: 10.1007/s11071-021-06380-9.

[17] S. H. Park and S. Y. Yi, "Active balancing control for unmanned bicycle using scissored-pair control moment gyroscope," Int. J. Control. Autom. Syst., vol. 18, no. 1, pp. 217-224, Jan. 2020, doi: 10.1007/s12555-018-0749-7.

[18] P. Seekhao, K. Tungpimolrut, and M. Parnichkun, "Development and control of a bicycle robot based on steering and pendulum balancing," Mechatronics, vol. 69, p. 102386, Aug. 2020, doi: 10.1016/j.mechatronics.2020.102386.

[19] M. A. Tofigh, M. J. Mahjoob, M. R. Hanachi, and M. Ayati, "Fractional sliding mode control for an autonomous two-wheeled vehicle equipped with an innovative gyroscopic actuator," Rob. Auton. Syst., vol. 140, p. 103756, Jun. 2021, doi: 10.1016/j.robot.2021.103756.

[20] B. T. Thanh and M. Parnichkun, "Balancing control of bicyrobo by particle swarm optimization-based structure-specified mixed

IAES Int J Rob \& Autom, Vol. 11, No. 1, March 2022: 43-61 
H2/Hœ control," Int. J. Adv. Robot. Syst., vol. 5, no. 4, pp. 395-402, Nov. 2008, doi: 10.5772/6235.

[21] A. Sikander and R. Prasad, "Reduced order modelling based control of two wheeled mobile robot," J. Intell. Manuf., vol. 30 , no. 3, pp. 1057-1067, Mar. 2019, doi: 10.1007/s10845-017-1309-3.

[22] D. K. Sambariya and A. K. Sharma, "An efficient approach for stability preservation in model order reduction using moment matching technique," in 2017 International Conference on Computer, Communications and Electronics, COMPTELIX 2017, 2017, pp. 478-483, doi: 10.1109/COMPTELIX.2017.8004017.

[23] D. K. Sambariya, A. K. Sharma, and T. Gupta, "Order reduction of air core transformer using continued fraction," J. Eng. Sci. Technol., vol. 14, no. 1, pp. 253-264, 2019.

[24] A. K. Sharma and D. K. Sambariya, "Mixed method application in order reduction of discrete system," in 2018 3rd IEEE International Conference on Recent Trends in Electronics, Information and Communication Technology, RTEICT 2018 Proceedings, 2018, pp. 1776-1780, doi: 10.1109/RTEICT42901.2018.9012361.

[25] A. K. Sharma and D. K. Sambariya, "Reduction of discrete systems using hybrid method," in Applications of Computing, Automation and Wireless Systems in Electrical Engineering, vol. 553, S. Mishra, Y. R. Sood, and A. Tomar, Eds. Singapore: Springer, 2019, pp. 959-968.

[26] A. K. Sharma and D. K. Sambariya, "Model reduction using Harris hawk algorithm and moment matching," Arch. Electr. Eng., vol. 70, no. 4, pp. 959-978, 2021, doi: 10.24425/aee.2021.138272.

[27] A. K. Sharma and D. K. Sambariya, "Mixed method for model order reduction using meta heuristic Harris hawk and Routh Hurwitz array technique," Indian J. Sci. Technol., vol. 14, no. 28, pp. 2380-2390, Jul. 2021, doi: 10.17485/ijst/v14i28.1054.

[28] D. K. Dhaked, D. Birla, A. K. Sharma, and D. K. Sambariya, Model order reduction of battery for smart battery management system. Modern Automotive Electrical Systems, Wiley-Scrivener Publishing, 2020.

[29] A. A. Heidari, S. Mirjalili, H. Faris, I. Aljarah, M. Mafarja, and H. Chen, "Harris hawks optimization: algorithm and applications," Futur. Gener. Comput. Syst., vol. 97, pp. 849-872, Aug. 2019, doi: 10.1016/j.future.2019.02.028.

[30] T. T. Bui, M. Parnichkun, and C. H. Le, "Structure-specified Hळ loop shaping control for balancing of bicycle robots: a particle swarm optimization approach," Proc. Inst. Mech. Eng. Part I J. Syst. Control Eng., vol. 224, no. 7, pp. 857-867, Nov. 2010, doi: 10.1243/09596518JSCE950.

[31] C. H. Nguyen, K. N. Vu, and D. H. Dao, "Applying order reduction model algorithm for balancing control problems of twowheeled mobile robot," in Proceedings of the 2013 IEEE 8th Conference on Industrial Electronics and Applications, ICIEA 2013, 2013, pp. 1302-1307, doi: 10.1109/ICIEA.2013.6566568.

\section{BIOGRAPHIES OF AUTHORS}
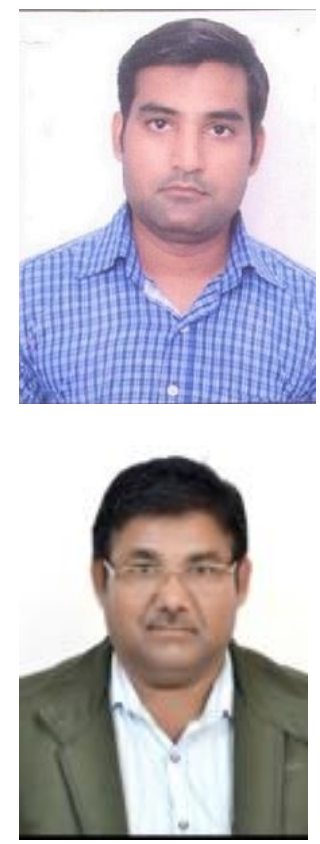

Aswant Kumar Sharma (iD S. SC P is research scholar in department of electrical engineering, Rajasthan technical university, Kota. The area of interest for research includes optimization techniques, (genetic based, swarm based, physics based and human behavior based), model order reduction and its application. The email address is aswantksharma@gmail.com.
Dhanesh Kumar Sambariya (D) SC SC P is Associate Professor in Department of Electrical Engineering, Rajasthan Technical University, Kota, 324010, India. He obtained his B.E. degree in Electrical Engineering and his M.E. degree in Power System engineering from the University of Rajasthan in 1994 and2009, respectively. He has completed his Ph. D. in Power System from Department of Electrical Engineering, Indian Institute of Technology Roorkee, Roorkee, 247667, India. He has published 64 research papers as 30 in reputed and/or SCI indexed journals and 34 in national and international conferences including IEEE. His fields of interest are controller design to mitigate the small signal stability problem in power system, model order reduction techniques, load frequency control in power system and application of optimization techniques including classical as well as heuristic soft computing techniques. He can be contacted at email: dksambariya@ rtu.ac.in. 